\title{
Growth patterns of patients with Noonan syndrome: correlation with age and genotype
}

\author{
Catie Cessans ${ }^{1, *}$, Virginie Ehlinger ${ }^{2 *}$, Catherine Arnaud ${ }^{2,3}$, Armelle Yart ${ }^{4}$, Yline Capri ${ }^{5}$, \\ Pascal Barat ${ }^{6}$, Benoit Cammas ${ }^{6}$, Didier Lacombe$^{7}$, Régis Coutant $^{8}$, Albert David ${ }^{9}$, \\ Sabine Baron ${ }^{10}$, Jacques Weill'11, Bruno Leheup ${ }^{12}$, Marc Nicolino ${ }^{13}$, \\ Jean-Pierre Salles ${ }^{1,14}$, Alain Verloes ${ }^{5}$, Maithé Tauber ${ }^{1,14}$, Hélène Cavé ${ }^{5}$ and \\ Thomas Edouard1,14
}

\begin{abstract}
${ }^{1}$ Endocrine, Bone Diseases, and Genetics Unit, Children's Hospital, Toulouse University Hospital, Toulouse, France, ${ }^{2}$ UMR 1027 INSERM, University of Toulouse Paul Sabatier, Toulouse, France, ${ }^{3}$ Clinical Epidemiology Unit, Toulouse University Hospital, Toulouse, France, ${ }^{4}$ INSERM UMR 1048, Institute of Cardiovascular and Metabolic Diseases (I2MC), University of Toulouse Paul Sabatier, Toulouse, France, ${ }^{5}$ Departments of Genetics, Robert-Debré University Hospital, APHP, Paris, France, ${ }^{6}$ Pediatric Endocrinology Department, Clinical investigation Centre (CIC 1401), Bordeaux University Hospital, Bordeaux, France, ${ }^{7}$ Genetics Department, Bordeaux University Hospital, EA4576, Bordeaux, France, ${ }^{8}$ Pediatric Endocrinology Department, Angers University Hospital, Angers, France, ${ }^{9}$ Genetics Department, Nantes University Hospital, Nantes, France, ${ }^{10}$ Pediatric Endocrine Unit, Nantes University Hospital, Nantes, France, ${ }^{11}$ Pediatric Endocrine Unit, Lille University Hospital, Lille, France, ${ }^{12}$ Pediatric and Genetics Unit, Nancy University Hospital, Vandoeuvre, France, ${ }^{13}$ Pediatric Endocrinology Department, Lyon University Pediatric Hospital, INSERM U.1060/UCBL/HCL, France, ${ }^{14}$ INSERM UMR 1043, Centre of Pathophysiology of Toulouse Purpan (CPTP), University of Toulouse Paul Sabatier, Toulouse, France *(C Cessans and V Ehlinger contributed equally to this work.)
\end{abstract}

\author{
Correspondence \\ should be addressed \\ to T Edouard \\ Email \\ edouard.t@chu-toulouse.fr
}

\begin{abstract}
Background: Growth patterns of patients with Noonan syndrome (NS) were established before the involved genes were identified.

Objective: The goal of this study was to compare growth parameters according to genotype in patients with NS. Subjects and methods: The study population included 420 patients (176 females and 244 males) harboring mutations in the PTPN11, SOS1, RAF1, or KRAS genes. NS-associated PTPN11 mutations (NS-PTPN11) and NS with multiple lentiginesassociated PTPN11 mutations (NSML-PTPN11) were distinguished. Birth measures and height and body mass index (BMI) measures at 2, 5, 10 years, and adulthood were compared with the general population and between genotypes.

Results: Patients with NS were shorter at birth (mean birth length standard deviation score (SDS): $-1.0 \pm 1.4 ; P<0.001$ ) and throughout childhood than the healthy population, with height SDS being $-2.1 \pm 1.3$ at 2 years, and $-2.1 \pm 1.2$ at 5 and 10 years and adulthood $(P<0.001)$. At birth, patients with NS-PTPN11 were significantly shorter and thinner than patients with NSML-PTPN11, SOS1, or KRAS. Growth retardation was significantly less severe and less frequent at 2 years in patients with NSML-PTPN11 and SOS1 than in patients with NS-PTPN11 $(P<0.001$ and $P=0.002$ respectively). Patients with NS had lower BMI at 10 years $(P<0.001)$. No difference between genotypes was demonstrated. Conclusion: Determining the growth patterns of patients with NS according to genotype should better inform clinicians about the natural course of growth in NS so that they can optimize the follow-up and management of these patients.

European Journal of Endocrinology

(2016) 174, 641-650
\end{abstract}

\section{Introduction}

Noonan syndrome (NS; Mendelian inheritance in man (MIM) \#163950) is a relatively frequent (estimated prevalence of 1 in 1000-2500 live births) autosomal dominant disorder characterized by facial dysmorphic
() 2016 European Society of Endocrinology Printed in Great Britain features, heart defects (i.e. pulmonary valve stenosis and hypertrophic cardiomyopathy), developmental delay, and short stature (1). These distinctive traits are shared, with variable severity, by NS-related diseases, namely NS

Published by Bioscientifica Ltd. 
with multiple lentigines (NSML; MIM \#151100), NS with loose anagen hair (MIM \#607721), cardiofaciocutaneous syndrome (MIM \#115150), Costello syndrome (MIM 218040), and neurofibromatosis type I (MIM \#162200). In the past decade, mutations in several genes encoding components of the RAS/MAPK signaling pathway were discovered to be involved in NS and NS-related diseases, and this group of disorders is now termed the RASopathies (2). They are one of the largest groups of multiple congenital anomaly diseases known.

The classical form of NS is principally associated with heterozygous missense mutations in four genes: PTPN11, SOS1, RAF1, and KRAS genes, accounting for $50,10,10$, and $<2 \%$, respectively, of the NS cases (1). A dozen genes have been found to be implicated in NS, but genetic screening remains negative in about $30 \%$ of patients with NS.

NSML, previously referred as LEOPARD syndrome (acronym for multiple Lentigines, Electrocardiographic conduction abnormalities, Ocular hypertelorism, Pulmonary stenosis, Abnormal genitalia, Retardation of growth, sensorineural Deafness), is closely related to NS. Indeed, because lentigines appear with age, these two syndromes might be difficult to differentiate in early life. NSML is allelic with NS, being mainly caused by PTPN11 (12q24.13) mutations ( $>80 \%$ of patients) and more rarely by $R A F 1$ (3p25.2) mutations $(3,4)$. So far, more than 60 mutations in PTPN11 have been associated with NS, which mainly affect the interaction between the $\mathrm{SH} 2$ and the protein tyrosine phosphatase (PTP) domains, and about 20 mutations, all targeting specific residues within the PTP domain, have been linked to NSML (5). The PTPN11 gene encodes Shp2, a widely expressed nonreceptor PTP that plays key roles in organism development and homeostasis by controlling major growth factors/hormone-triggered signaling pathways, notably the RAS/MAPK pathway (6). From a biochemical point of view, it has been shown that NScausing mutations induce hyperactivation of the phosphatase (gain-of-function mutation), while NSML-associated mutations result in reduced Shp2 catalytic activity (inactivating mutation) $(7,8)$. How NS-Shp2 and NSML-Shp2 mutants can result in related syndromes while displaying opposite biochemical effects is still a matter of debate (9). Interestingly, a differential impact of these mutants on the phosphatidylinositol 3-kinase (PI3K)/Akt signaling pathway has been causally linked to the development of hypertrophic cardiomyopathy, which is preferentially found in patients with NSML $(10,11)$.

Proportionate short stature, reported in more than $70 \%$ of affected patients, is one of the main clinical symptoms of NS that lead to the diagnosis (12). Specific growth charts were established more than 25 years ago $(13,14)$ before the genes involved in NS were identified. The discovery of these genes made it possible to look for genotype-phenotype correlations in growth patterns. However, to our knowledge, only one study investigated the growth characteristics according to genotype in 127 patients with NS and 10 patients with NS-related diseases, with interesting preliminary results (15). In this study, growth parameters (height, weight, and body mass index (BMI)) were converted to age-specific and sex-specific standard deviations on the basis of children's growth standards, and then cumulated before searching for differences between genotypes. As a result, variations according to age and genotype could not be investigated.

In this study, we aimed to describe the growth characteristics (i.e. measurements at birth, height, and BMI) of patients with NS and NSML according to their age and genotype, and evaluate whether mutations in the different genes involved in NS and NSML may have differential impact in growth. To achieve this goal, we took advantage of a French national database and present the growth parameters at different ages according to their genotype in 420 patients with NS or NSML harboring mutations in the PTPN11, SOS1, RAF1, or KRAS genes.

\section{Subjects and methods}

\section{Patient population}

The majority of French patients with NS and NS-related disorders are referred for molecular testing to the Department of Genetics of Robert-Debré Hospital (Paris, France). The clinical data are recorded by the clinicians on standard datasheets. The data include, among other features, the gestational age and measurements at birth (weight, length, and head circumference), and the height and weight at the time of consultation, at 2, 5, 10 years of age, and in adulthood. Treatment with growth hormone $(\mathrm{GH})$ is also recorded.

The study was approved by the Paris-Bichat-Claude Bernard Institutional Review Board ( $\left.{ }^{\circ} 2003 / 15\right)$ and informed consent was obtained from legal guardians for genetic analyses and for building up the database.

Inclusion criteria for our study were a diagnosis of NS or NSML between 2002 and 2012, caused by germline mutations in one of the following genes: PTPN11, SOS1, RAF1, or KRAS. Two types of PTPN11 mutations were distinguished: NS-associated PTPN11 mutations 
(NS-PTPN11) (gain-of-function mutation) and NSML-associated PTPN11 mutations (NSML-PTPN11) (loss-of-function mutation). For patients treated with $\mathrm{GH}$, growth data under treatment were excluded.

Between 2002 and 2012, germline mutations in the PTPN11, SOS1, RAF1, or KRAS genes were found in 999 patients. Among the NS cohort, there were 803 index patients and 196 related patients. The median age at the time of molecular testing was 6.2 years (interquartile range (IQR): $1.3-13.6)$ in index patients and 27.6 years (IQR: 5.6-36.5) in related patients. To ensure better homogeneity of the results, analyses were only performed in index patients. Data on the growth parameters were missing in numerous patients because of the retrospective study design. To be included in the study, patients had to have at least one height measurement among the four key ages recorded on standard datasheets (at 2, 5, and 10 years of age, and in adulthood). Ultimately, 420 patients (176 females and 244 males) were included. Gestational age and birth measurements were available in most patients of our cohort (339 of 420 patients, 81\%). Simultaneous weight and height measurements, allowing BMI calculation, were available for 269 patients (64\%).

To exclude a potential selection bias, we compared sex ratio and frequencies of different genotypes between our cohort $(n=420)$ and index patients that were excluded $(n=383)$. These two data were similar between the two groups ( $P=0.433$ and 0.127 , respectively, $\chi^{2}$ test).

In our cohort of 420 index patients, NS-PTPN11 mutations were found in 300 (72\%) patients, NSML-PTPN11 mutations in 34 (8\%), SOS1 mutations in 41 (10\%), RAF1 mutations in 31 (7\%), and KRAS mutations in 14 (3\%) patients.

Growth hormone therapy was initiated in 58 patients (14\%) at a mean age of $8.2 \pm 3.9$ years and for these patients the growth parameters obtained after the start of the treatment were excluded from the analysis. Moreover, data about $\mathrm{GH}$ treatment were missing in 90 patients (21\%) and growth data were consequently excluded in these patients after the age of 2 years.

\section{Auxological parameters}

Weight, height, and head circumference at birth were expressed as standard deviation score (SDS) with reference to gestational age according to Usher and McLean (16). Small for gestational age (SGA) was defined as birth height and/or birth weight SDS below -2 .

BMI was calculated as the ratio of weight in kilograms divided by the square of height in meters. Height and
BMI measurements were converted to age-specific and sex-specific SDS on the basis of published reference data (17). Short stature was defined as height SDS below -2 and thinness as BMI SDS below -2 .

\section{Molecular analysis}

DNA samples were obtained from peripheral leukocytes. Mutation screening was performed by direct bidirectional sequencing of exons and their flanking intron-exon boundaries. The entire coding region of PTPN11, SOS1, $R A F 1$, and $K R A S$ was tested in all patients. Primers and PCR conditions are available on request.

The PCR products were sequenced (BigDye Terminator Cycle Sequencing Ready Reaction Kit, Applied Biosystems) and reaction products run on an automated capillary sequencer (ABI PRISM 3100 Genetic Analyzer, Applied Biosystems). Sequences were aligned using SeqScape Analysis Software (Applied Biosystems) and compared with the reference sequences for genomic DNA and mRNA. GenBank accession numbers for genomic and mRNA reference sequences, respectively, are as follows: PTPN11 (NC_000012 and NM_002834), SOS1 (NC_000002 and NM_005633), RAF1 (NC_000007 and NM_004333), and KRAS (NC_000012 and NM_033360, isoform a) or (NM_004985, isoform b).

\section{Statistical analysis}

Dichotomous variables are presented as percentages and compared between the five genotype groups using Fisher's exact test or $\chi^{2}$ test when applicable. Birth measures, height, and BMI measures at age 2, 5, and 10 years ( \pm 6 months) and in adulthood ( $>20$ years of age) are described as mean \pm S.D. First, means SDS for the entire NS sample was compared with those of the general population. One-sample Student's t-test, assuming an average $z$-score of 0 in the general population, was used for normally distributed data; one-sample median test (Wilcoxon signed-rank test) was used otherwise, assuming a hypothesized median of 0 in the general population. $P<0.05$ was considered to be statistically significant. Then, ANOVA was applied to compare the measures between the five groups at a 5\% level. The normality of the measures was tested in each genotype group by Skewness and Kurtosis test, whereas the homogeneity of variances across groups was assessed using Levene's test. Given the robustness of ANOVA to nonnormality and heteroscedasticity, these tests were applied at a threshold of 0.001 . Nonnormally distributed 
Table 1 Birth measurements in patients with Noonan syndrome according to genotype.

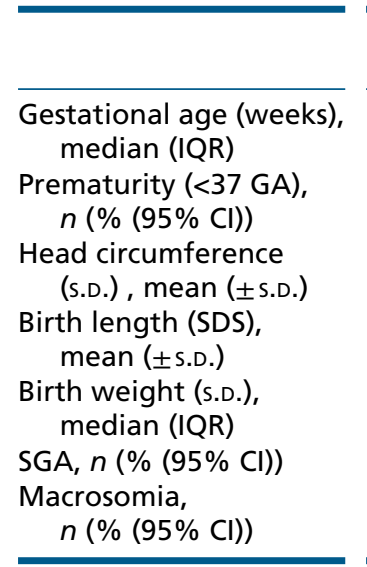

\begin{tabular}{|c|c|}
\hline $\begin{array}{c}\text { NS-PTPN11 } \\
n=244\end{array}$ & $\begin{array}{c}\text { NSML-PTPN11 } \\
n=25\end{array}$ \\
\hline $39(37 ; 40)^{c, 2}$ & $39(38 ; 40)$ \\
\hline $43(18(13 ; 22))^{c, 3}$ & $4(16(0 ; 31))$ \\
\hline$-0.6(1.5)^{a, b, c, d, 1}$ & $0.5(1.7)$ \\
\hline$-1.2(1.3)^{a, b, d, 1}$ & $-0.2(1.4)$ \\
\hline$-0.1(-0.9 ; 0.5)^{a, b, d, 2}$ & $1.3(-0.3 ; 2.5)$ \\
\hline $\begin{array}{c}66(29(23 ; 35)) \\
14(6(3 \cdot 10)))^{a, b, d, F}\end{array}$ & $4(16(4 ; 36))$ \\
\hline $14(6(3 ; 10))^{a, b, a, r}$ & $10(40(21 ; 61))$ \\
\hline
\end{tabular}

\begin{tabular}{c}
\hline $\begin{array}{c}\text { Sos1 } \\
n=35\end{array}$ \\
\hline $38(37 ; 39)$ \\
$8(23(8 ; 37))$ \\
$0.5(1.5)$ \\
$-0.4(1.2)$ \\
$1.0(-0.2 ; 1.7)$ \\
$6(17(7 ; 34))$ \\
$7(20(8 ; 37))$
\end{tabular}

\begin{tabular}{c}
\hline $\begin{array}{c}\text { RAF1 } \\
n=25\end{array}$ \\
\hline $36(36 ; 39)$ \\
$13(52(31 ; 73))$ \\
$1.1(1.4)$ \\
$-1.0(1.5)$ \\
$0.5(-0.4 ; 1.6)$ \\
$5(21(7 ; 42))$ \\
$3(12(3 ; 32))$
\end{tabular}

\begin{tabular}{|c|c|}
\hline $\begin{array}{l}\text { KRAS } \\
n=10\end{array}$ & $P$-value \\
\hline $37(36 ; 38)$ & $0.006^{\ddagger}$ \\
\hline $4(40(3 ; 77))$ & $0.002^{\mathrm{F}}$ \\
\hline $1.1(1.1)$ & $<0.001^{\dagger}$ \\
\hline $0.5(1.3)$ & $<0.001^{\dagger}$ \\
\hline $0.7(0.0 ; 3.0)$ & $<0.001^{\ddagger}$ \\
\hline $\begin{array}{c}0(0(0 ; 31)) \\
4(40(12 ; 74))\end{array}$ & $\begin{array}{l}0.129^{F} \\
<0.001^{F}\end{array}$ \\
\hline
\end{tabular}

$P$-values were calculated using the ANOVA $\left(^{+}\right)$or Kruskal-Wallis $\left(^{\ddagger}\right)$ tests for continous variables and Fisher's exact test (F) for dichotomous variables. For pairwise group, comparisons with Šidák correction were done to adjust for multiple testing $(P<0.013$ considered as significant).

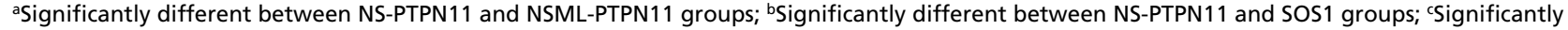
different between NS-PTPN11 and RAF1 groups; 'Significantly different between NS-PTPN11 and KRAS groups.

${ }^{1}$ Student's $t$-test; ${ }^{2}$ Mann-Whitney U test; ${ }^{3} \chi^{2}$ test.

Adapted from Usher \& McLean (16).

measures were expressed as medians and IQRs and were compared across groups using Kruskal-Wallis test.

In the case of significant results, pairwise comparisons between the NS-PTPN11 genotype and each of the other groups were conducted using Student's $t$-test for normally distributed data, and Mann-Whitney $\mathrm{U}$ test. Because of the multiplicity of the tests, these comparisons were conducted at the 0.013 threshold (Šidák correction adjustment for four tests).

Statistical analyses were performed using Stata Statistical Software, version 11 for Windows (StataCorp).

\section{Results}

\section{Birth measurements}

Although most patients were born full-term, frequency of prematurity ( $<37$ weeks of gestational age) was significantly higher (72 of 339 patients, $21 \%$ ) in patients with NS compared with the general population in France (7\%) (18). Significant differences were found in all genotypes $(P<0.001$ for one-sample $t$-test of comparison with the general population), except for patients with NSML $(P=0.094)$.

Compared with healthy neonates, patients with NS were shorter (mean birth length SDS: $-1.0 \pm 1.4 ; P<0.001$, one-sample $t$-test) and had smaller head circumference (mean SDS: $-0.2 \pm 1.6 ; P=0.010$, one sample $t$-test); birth weight was similar (median SDS: $0.0, \mathrm{IQR}=(-0.8 ; 0.9)$; $P=0.265$, Wilcoxon signed-rank test). Birth measurements varied greatly according to the genotype. Patients with NS-PTPN11 mutations had significantly smaller head circumference compared with patients with other genotypes $(P<0.001$ for all). Moreover, patients with NS-PTPN11 were significantly shorter and thinner than patients with NSML-PTPN11, SOS1, and KRAS (birth length: $P<0.001$ for all, birth weight: $P<0.001$ for patients with NS-PTPN11 compared with NSML-PTPN11 and SOS1, $P=0.008$ for patients with KRAS compared with patients with NS-PTPN11), but did not differ from patients with RAF1 (Table 1).

In accordance with these data, frequency of SGA (birth height and/or birth weight SDS $<-2$ ) was significantly higher (81 of 339 patients, 24\%) in patients with NS compared with the general population in France (5\%) (18). Significant differences were found for all genotypes $(P<0.001$ for patients with NS-PTPN11, SOS1, and RAF1, and $P=0.012$ for patients with NS-PTPN11), except for patients with KRAS $(P=0.468)$ (Table 1$)$.

As shown in Fig. 1 and Supplementary Table 1, see section on supplementary data given at the end of this article SGA predominated on length rather than weight.

Macrosomia was present in 38 patients (11\%), especially in patients with NSML-PTPN11 (40\%) and KRAS (40\%).

\section{Height according to age and genotype}

Compared with the age-specific and sex-specific reference ranges, patients with NS on average were significantly shorter throughout childhood, with height SDS being stable with age: $-2.1 \pm 1.3$ at 2 years of age, and $-2.1 \pm 1.2$ at 5 and 10 years of age and in adulthood $(P<0.001$ for one-sample $t$-test of comparison with the general population at all ages).

Height $(\mathrm{cm})$ values between 1 month and adulthood from male and female patients with NS were plotted 


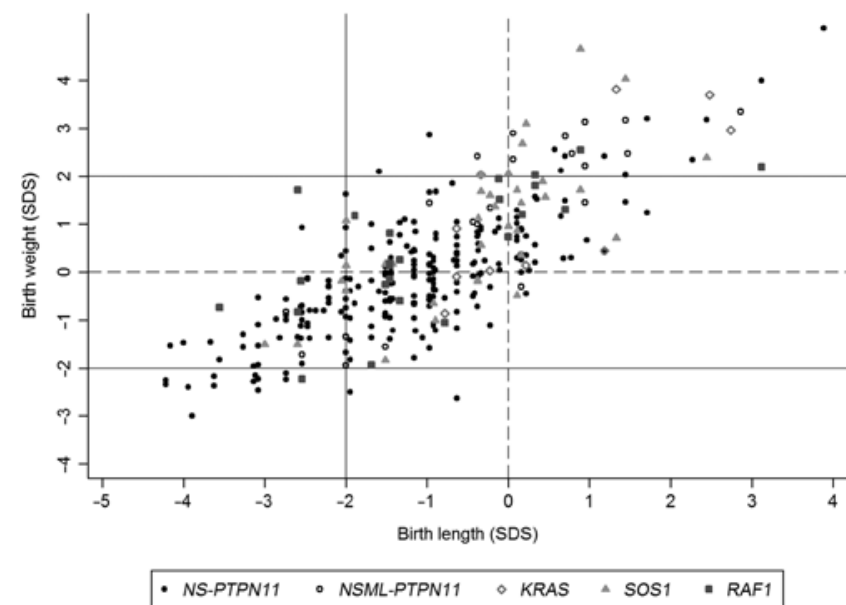

Figure 1

Distribution of birth length and birth weight SDS in patients with Noonan syndrome according to genotype.

Adapted from Usher \& McLean (16).

according to age onto appropriate gender-specific WHO Child Growth Standards (Fig. 2A, all values $\geq 20$ years were gathered together); a total of 619 data points were available from 420 patients. As previously described for patients with NS, mean height in both genders followed -2 SDS from childhood to adulthood.

To further investigate the evolution of height according to age and genotype, height values obtained at all ages ( $\geq 1$ month) were converted to age-specific and sex-specific SDS on the basis of the WHO Child Growth Standards and were represented according to age and genotype (Fig. 2B). Interestingly, growth retardation was significantly less severe and less frequent at 2 years of age in patients with NSML-PTPN11 and SOS1 compared with patients with NSPTPN11 ( $P<0.001$ and $P=0.002$, respectively) (Table 2 and Fig. 2B). Although a similar trend was observed at the other ages, no statistical difference was found, probably due to the small number of patients. No statistical difference was found between patients with NS-PTPN11, RAF1, and KRAS.

For patients with NS-PTPN11, median final height was $158 \mathrm{~cm}$ for males (IQR: $(155 ; 160))$ and $150 \mathrm{~cm}$ for females (IQR: $(144 ; 153)$ ), corresponding to height SDS of -2.5 and -2.0 , respectively.

Due to the small size of the subcohorts, it was not possible to precisely investigate gender differences between the genotypes. However, it is interesting to note that height at all time points (at birth, 2, 5, and 10 years of age, and adulthood) was higher in male patients with NSMLPTPN11 compared with male patients with NS-PTPN11, whereas there was no difference between females.
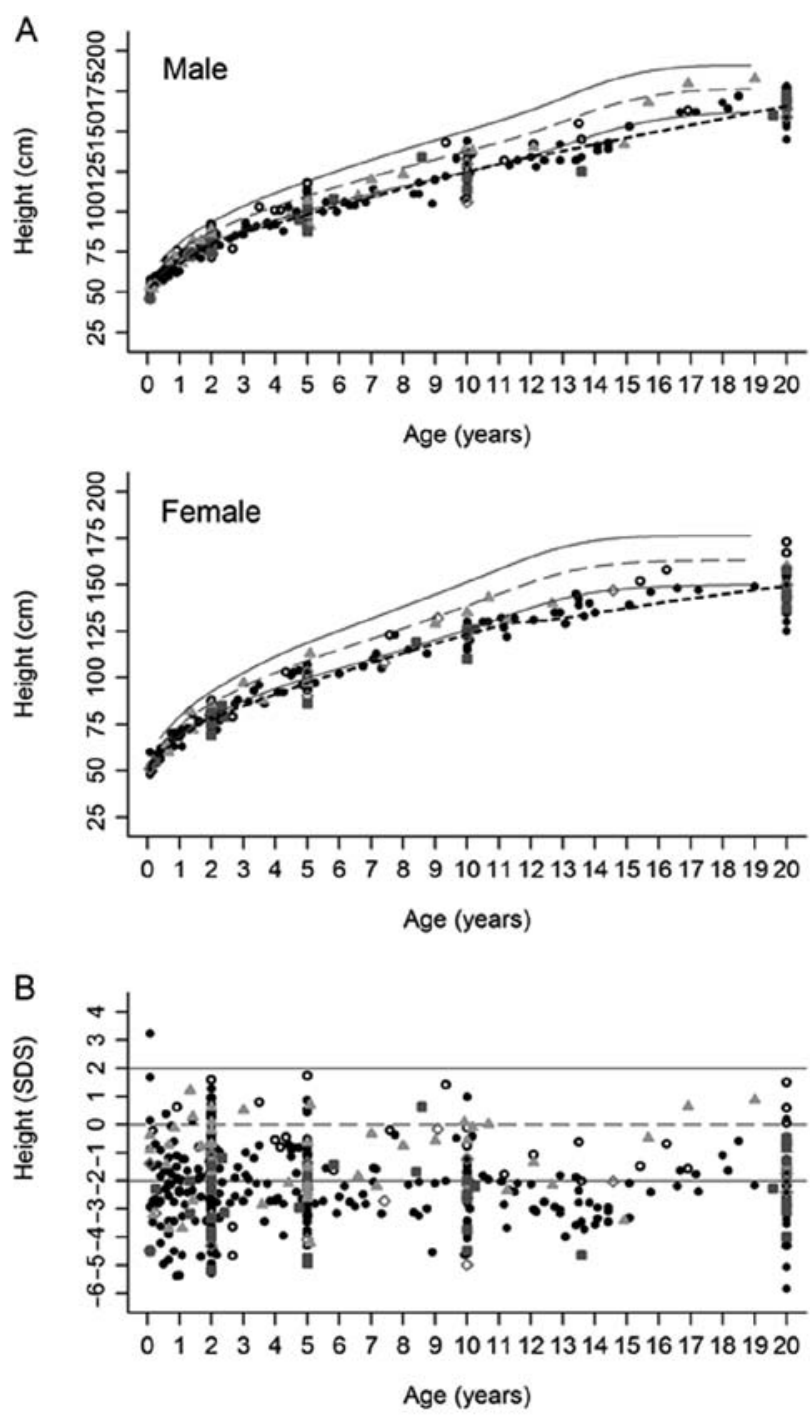

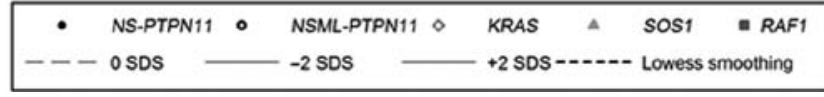

Figure 2

Evolution of height in patients with Noonan syndrome according to age, gender, and genotype. (A) Height (cm) values plotted according to age onto appropriate gender-specific WHO Child Growth Standards. (B) Height SDS values (WHO Child Growth Standards) according to age and genotype. SDS, standard deviation score.

\section{BMI according to age and genotype}

Given the very low numbers in certain genotype groups, Skewness and Kurtosis test could not be applied. BMI measures at 2, 5, and 10 years of age are given in Table 3 as median range and IQR. Compared with the age-specific and sex-specific reference ranges, the mean SDS of BMI 
Table 2 Height (WHO Child Growth Standards) in patients with Noonan syndrome according to age and genotype.

\begin{tabular}{|c|c|c|c|c|c|c|}
\hline & NS-PTPN11 & NSML-PTPN11 & sos1 & RAF1 & KRAS & P-value \\
\hline \multicolumn{7}{|l|}{2 years } \\
\hline$n$ & 153 & 15 & 12 & 10 & 5 & \\
\hline Height (SDS), median (IQR) & $-2.1(-3.0 ;-1.5)^{a, b, 3}$ & $-1.0(-2.0 ; 0.4)$ & $-1.1(-1.7 ;-0.2)$ & $-3.2(-3.8 ;-2.0)$ & $-1.2(-1.5 ;-1.0)$ & $<0.001^{\ddagger}$ \\
\hline $\begin{array}{l}\text { Height }<-2 \text { SDS } \\
\quad n(\%(95 \% \mathrm{Cl}))\end{array}$ & $90(59(50 ; 67))^{a, b, 1}$ & $4(27(8 ; 55))$ & $2(17(2 ; 48))$ & $8(80(44 ; 97))$ & $1(20(0 ; 72))$ & $0.001^{\mathrm{F}}$ \\
\hline \multicolumn{7}{|l|}{5 years } \\
\hline$n$ & 66 & 8 & 8 & 4 & 5 & \\
\hline Height (SDS), median (IQR) & $-2.4(-2.8 ;-1.3)$ & $-1.7(-2.6 ;-0.9)$ & $-2.3(-2.6 ;-1.1)$ & $-3.8(-4.8 ;-2.4)$ & $-2.3(-4.1 ;-2.2)$ & $0.204^{\ddagger}$ \\
\hline $\begin{array}{l}\text { Height }<-2 \text { SDS } \\
\quad n(\%(95 \% \mathrm{Cl}))\end{array}$ & $38(58(45 ; 70))^{b, 1}$ & $2(25(3 ; 65))$ & $5(62(24 ; 91))$ & $3(75(19 ; 99))$ & $4(80(28 ; 99))$ & $0.325^{\mathrm{F}}$ \\
\hline \multicolumn{7}{|l|}{10 years } \\
\hline$n$ & 37 & 5 & 5 & 5 & 4 & \\
\hline Height (SDS), median (IQR) & $-2.1(-2.4 ;-1.5)$ & $-1.2(-1.7 ;-0.7)$ & $-0.6(-2.3 ;-0.1)$ & $-2.6(-3.7 ;-2.5)$ & $-2.4(-3.8 ;-1.7)$ & $0.049^{\ddagger}$ \\
\hline $\begin{array}{l}\text { Height }<-2 \text { SDS } \\
\quad n(\%(95 \% \mathrm{Cl}))\end{array}$ & $20(54(37 ; 70))$ & $1(20(1 ; 72))$ & $2(40(5 ; 85))$ & $4(80(28 ; 99))$ & $3(75(19 ; 99))$ & $0.338^{F}$ \\
\hline \multicolumn{7}{|l|}{ Adulthood } \\
\hline$n$ & 32 & 11 & 6 & 6 & 3 & \\
\hline Height (SDS), median (IQR) & $-2.3(-2.9 ;-1.8)$ & $-1.2(-2.2 ; 0.1)$ & $-1.2(-2.8 ;-0.6)$ & $-2.0(-3.1 ;-0.8)$ & $-2(-2.4 ;-1.7)$ & $0.088^{\ddagger}$ \\
\hline $\begin{array}{l}\text { Height }<-2 \text { SDS } \\
\quad n(\%(95 \% \mathrm{Cl}))\end{array}$ & $21(66(47 ; 81))$ & $3(27(6 ; 61))$ & $2(33(4 ; 78))$ & $3(50(12 ; 88))$ & $2(67(9 ; 99))$ & $0.161^{F}$ \\
\hline \multicolumn{7}{|l|}{ Adult males } \\
\hline$n$ & 13 & 4 & 3 & 2 & 2 & \\
\hline $\begin{array}{l}\text { Height }(\mathrm{cm}) \text {, median }(\mathrm{IQR}) \\
\text { Adult females }\end{array}$ & $158(155 ; 160)^{a, 3}$ & $169(164 ; 175)$ & $170(166 ; 172)$ & $170(167 ; 173)$ & $162(159 ; 164)$ & $0.015^{\ddagger}$ \\
\hline$n$ & 19 & 7 & 3 & 4 & 1 & \\
\hline Height (cm), median (IQR) & $150(144 ; 153)$ & $155(146 ; 167)$ & $145(145 ; 160)$ & $144(140 ; 152)$ & $150(150 ; 150)$ & $0.606^{\ddagger}$ \\
\hline
\end{tabular}

was 0.2 at 2 years $(P=0.185$; one sample $t$-test $), 0.1$ at 5 years $(P=0.563)$, and -0.7 at 10 years $(P<0.001)$.

BMI $\left(\mathrm{kg} / \mathrm{m}^{2}\right)$ values between 1 month and 19 years from male and female patients with NS were plotted according to age onto the appropriate gender-specific WHO Child Growth Standards (Fig. 3A); a total of 352 data points were available from 269 patients. BMI was normal in patients with NS until 10 years, after which it remained in the lower normal range.

Then, the BMI values converted to age-specific and sex-specific SDS on the basis of the WHO Child Growth Standards were represented according to age and genotype (Fig. 3B). No difference between genotypes was found (Table 3 and Fig. 3B). Due to limited data, BMI could not be analyzed in the adult patients with NS.

\section{Discussion}

In this study, we describe the growth patterns of a large cohort of patients with NS according to age and genotype. The frequencies of the genotypes were similar to those previously described in patients with a genetically confirmed diagnosis of NS, with a vast majority of patients with NS-PTPN11 (about 70\%) (1).

First, we compared characteristics of the entire NS cohort with the general healthy population. We found that frequencies of prematurity (21\%) and SGA (24\%) were high in patients with NS compared with the general population in France (7 and 5\% respectively) (18). Patients with NS were significantly shorter at birth compared with healthy neonates, but had normal birth weight and head circumference, indicating an asymetrical SGA. The subsequent evolution of postnatal growth in the patients with NS was similar to that reported by Ranke et al. (13) and Witt et al. (14), with a mean height following -2 SDS in males and females from childhood to adulthood. However, these growth patterns significantly varied according to the genotype. At birth, patients with NS-PTPN11 and RAF1 had more severely impaired growth than the other genotypes. This shorter size at birth of patients with NS-PTPN11 was reported by Limal et al. (19), but not by Yoshida et al. (20). Conversely, we found that neonates with KRAS mutations were often larger for gestational age and had an increased frequency of macrosomia. In 
Table 3 BMI (WHO Child Growth Standards) in patients with Noonan syndrome according to age and genotype.

\begin{tabular}{|c|c|c|c|c|c|c|}
\hline & NS-PTPN11 & NSML-PTPN11 & sos1 & RAF1 & KRAS & $P$-value \\
\hline \multicolumn{7}{|l|}{2 years } \\
\hline$n$ & 66 & 5 & 4 & 4 & 1 & \\
\hline BMI (SDS), median (IQR) & $0.2(-0.8 ; 1.0)$ & $0.5(-0.2 ; 0.9)$ & $0.4(-0.2 ; 1.7)$ & $0.3(-0.1 ; 1.1)$ & $-1.4(-1.4 ;-1.4)$ & $0.596^{\ddagger}$ \\
\hline $\mathrm{BMI}<-2$ SDS, n $(\%(95 \% \mathrm{CI}))$ & $0(0(0 ; 5))$ & $1(20(1 ; 72))$ & $0(0(0 ; 60))$ & $0(0(0 ; 60))$ & $0(0(0 ; 98))$ & $0.175^{\mathrm{F}}$ \\
\hline \multicolumn{7}{|l|}{5 years } \\
\hline$n$ & 35 & 2 & 4 & 1 & 2 & \\
\hline BMI (SDS), median (IQR) & $0.0(-0.5 ; 0.7)$ & $-1.1(-1.2 ;-0.9)$ & $0.0(-0.7 ; 0.7)$ & $2.1(2.1 ; 2.1)$ & $-0.3(-1.2 ; 0.6)$ & 0.106 \\
\hline $\mathrm{BMI}<-2$ SDS, n $(\%(95 \% \mathrm{CI}))$ & $1(3(0 ; 15))$ & $0(0(0 ; 84))$ & $0(0(0 ; 60))$ & $0(0(0 ; 98))$ & $0(0(0 ; 84))$ & $1.000^{\mathrm{F}}$ \\
\hline \multicolumn{7}{|l|}{10 years } \\
\hline$n$ & 23 & 2 & 4 & 1 & 1 & \\
\hline BMI (SDS), median (IQR) & $-0.9(-1.5 ;-0.2)$ & $-0.5(-1.1 ; 0.1)$ & $-0.4(-0.9 ; 0.0)$ & $-0.6(-0.6 ;-0.6)$ & $-2.2(-2.2 ;-2.2)$ & $0.407^{\ddagger}$ \\
\hline $\mathrm{BMI}<-2$ SDS, n (\% (95\% CI)) & $1(4(0 ; 22))$ & $0(0(0 ; 84))$ & $0(0(0 ; 60))$ & $0(0(0 ; 98))$ & $1(100(3 ; 100))$ & $0.159^{F}$ \\
\hline
\end{tabular}

the initial description of patients with $R A F 1$, macrosomia was found in about a quarter of patients (6 of 22 patients, 27\%) and was associated with polyhydramnios (6 of 19 patients, 31\%) (3). Polyhydramnios may also explain the higher frequency of prematurity in these patients.

Concerning postnatal growth, previous studies have reported differences in the frequency of short stature between genotypes. Thus, by reviewing the growth data available in published studies, we found that short stature affected $73 \%$ of patients with NS-PTPN11, 85\% of patients with $R A F 1,84 \%$ of patients with $K R A S, 35 \%$ of patients with SOS1, and 18\% of patients with NS-PTPN11 (Supplementary Table 2). However, all these studies reported the frequency of short stature by pooling data expressed in SDS from patients of different ages, precluding the description of growth according to age. In our study, patients with NSML-PTPN11 and SOS1 were taller at birth and during infancy compared with patients with NS-PTPN11, RAF1, and KRAS. Although a similar trend was observed at the other ages, no statistical difference was found, probably due to the small number of patients, therefore definite conclusion could not be drawn. This less severe growth impairment was previously suggested for patients with SOS1 (15), but has never been shown for patients with NSML-PTPN11. These data may provide insights into the mechanisms underlying growth retardation, which are still incompletely understood. Similar to the origins described for the heart and craniofacial defects observed in NS $(21,22,23)$, the enhancement of RAS/ MAPK activation seems to be crucial. Indeed, in several NS mouse models carrying a PTPN11, SOS, or RAF1 mutation, chronic inhibition of the RAS/MAPK pathway has been shown to improve growth velocity $(24,25,26)$. Regarding the mechanisms involved, it has been reported that a NSPTPN11 mutant impairs the systemic production of insu- lin-like growth factor-1 (IGF-1), the biological mediator of GH acting on growth plate, through a hyperactivation of the RAS/MAPK signaling pathway (25). These experimental data are in accordance with clinical data indicating partial GH insensitivity in patients with NS $(19,27)$. Thus, different IGF-1 levels may explain the differences of height between genotypes. In addition, a possible direct effect (IGF-1 independent) of RAS/MAPK activation on growth plate and longitudinal bone growth may also be involved. Growth retardation related to abnormal differentiation of chondrocytes was reported in a mouse model expressing constitutively active mutant of the MAPK/ MEK1 (28) and in a mouse model deficient in neurofibromin 1, a negative regulator of RAS/MAPK activation (29). Moreover, growth plate abnormalities were also observed in achondroplasia, a common skeletal dysplasia related to gain-of-function mutation in the fibroblast growth factor receptor 3 gene (FGFR3) leading to prolonged activation of RAS/MAPK at the growth plate level (30).

The difference in height between genotypes in our survey may thus be explained by differences in the degree of activation of the RAS/MAPK signaling pathway or by differential, genotype-dependent, tissue specificity. However, no genotype-phenotype correlation studies have been reported to quantitatively assess the level of RAS/MAPK hyperactivation or to document the tissue/ organ pattern of RAS/MAPK dysregulation. Alternatively, some specific mutants may induce dysregulation of other signaling pathways, which might counteract or synergize with RAS/MAPK hyperactivation. In particular, hyperactivation of the PI3K/Akt signaling pathway has been causally linked to NSML pathophysiology, notably hypertrophic cardiomyopathy $(10,11)$, and constitutional hyperactivation of the PI3K/Akt signaling pathway is associated with overgrowth syndrome $(31,32)$, suggesting a positive regulating role in growth. Thus, the hyperactivation of PI3K/ 

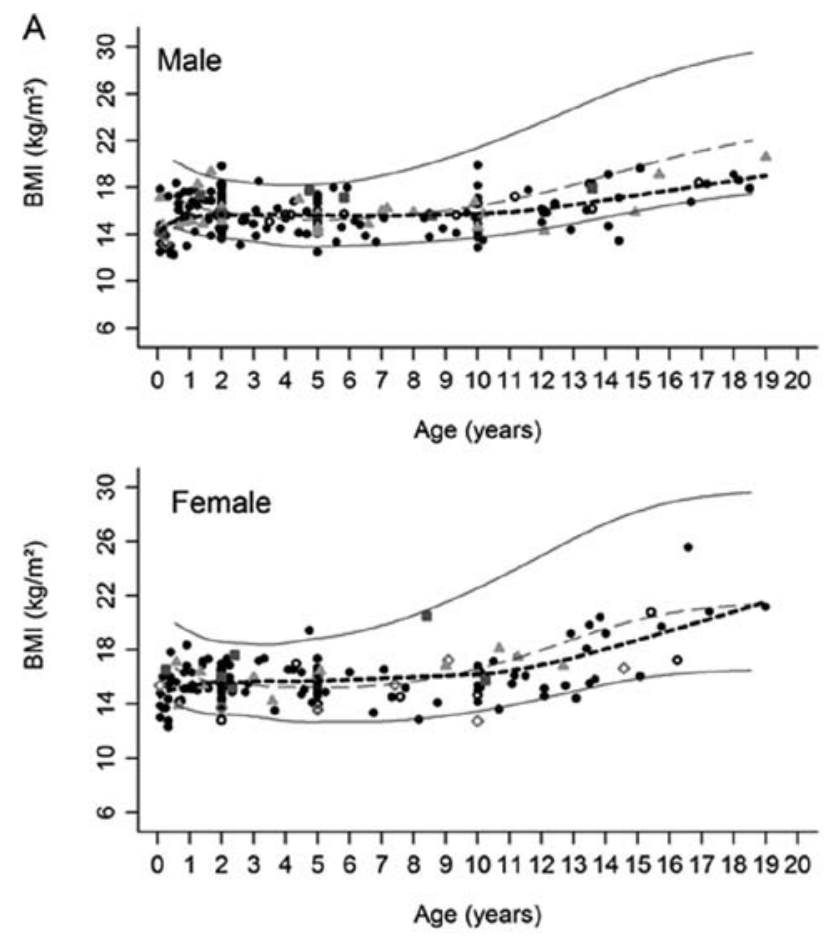

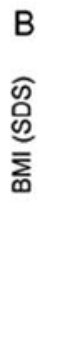

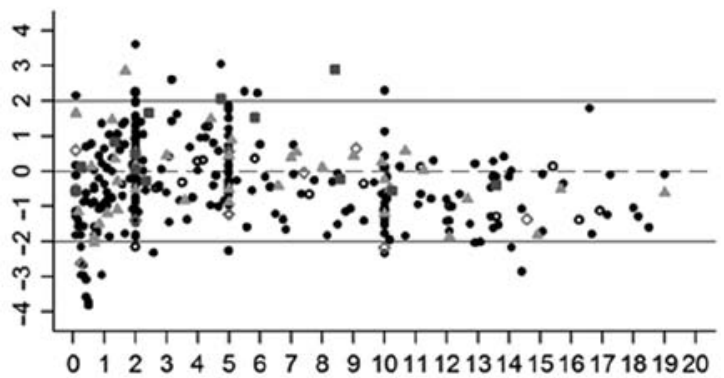

Age (years)

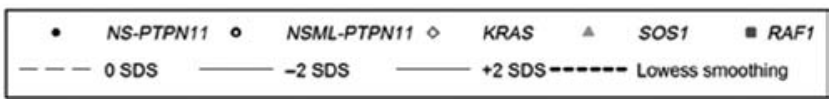

\section{Figure 3}

Evolution of $\mathrm{BMI}$ in patients with Noonan syndrome according to age, gender, and genotype. (A) BMI $\left(\mathrm{kg} / \mathrm{m}^{2}\right)$ values plotted according to age onto appropriate gender-specific WHO Child Growth Standards. (B) BMI SDS values (WHO Child Growth Standards) according to age and genotype.

Akt found in NSML, and possibly other RASopathies, may soften growth delay in these patients.

Another interesting observation in our study was that patients with NS, with the exception of patients with RAF1 mutations, had normal BMI during the first 5 years of life and then displayed relative 'thinness' with a BMI in the lower normal range. Lower BMI values were also reported in children with NS by Malaquias et al. (15) and, in line with these data, a survey showed that adults with NS rarely develop overweight or obesity (33). This suggested that NS-associated mutations could modify energy metabolism regulation, and this hypothesis has been recently confirmed in a mouse model expressing a NSML-PTPN11 (loss-of-function) mutation (34). NSML mice display a lean phenotype associating reduced adiposity with resistance to diet-induced obesity and improved carbohydrate metabolism, which could be converted by the inhibition of RAS/MAPK and PI3K signaling pathway activation, respectively. Other studies are needed to explore the consequences of other NS mutants on metabolism and to understand how RAF1 mutations, which also affect RAS/MAPK signaling, result in opposite phenotypes.

The strength of this study lies in the high number of patients and the absence of recruitment bias. Indeed, whatever the presenting sign (i.e. dysmorphic features, heart defects, developmental delay, or short stature) or the referring physician (i.e. geneticist, cardiologist, or endocrinologist), all molecular testing was carried out in the same Department of Genetics (Robert-Debre Hospital). However, except for the patients with NS-PTPN11, this study was limited by the small quantity of growth data in the other subcohorts, especially after the age of 2 years. Another important limitation was missing data due to the retrospective design of the study. For example, the presence of associated diseases that can modify growth (e.g. heart failure and failure to thrive) and the hormonal status (e.g. IGFI levels) were unavailable. Finally, from the initial cohort of index patients with NS from Robert-Debré Hospital database, about half of them were included in our study. Despite similar sex ratio and frequencies of different genotypes between these two groups, a selection bias cannot be fully excluded.

\section{Conclusion}

This is the first study trying to describe the growth patterns of patients with NS according to age and genotype. We provided some evidence that patients with NSML-PTPN11 and SOS1 were taller at birth and during infancy compared with other genotypes.

Further prospective studies are required to better delineate the growth patterns of patients with NS from childhood to adulthood and perform more robust genotype-phenotype correlation analyses. These data are needed to better inform clinicians about the natural course of growth in patients with NS, thereby allowing them to adjust the follow-up and management of these patients. 
Supplementary data

This is linked to the online version of the paper at http://dx.doi.org/10.1530/ EJE-15-0922.

\section{Declaration of interest}

The authors declare that there is no conflict of interest that could be perceived as prejudicing the impartiality of the research reported.

\section{Funding}

This work has been supported in part by grants from the Programme Hospitalier de Recherche Clinique (PHRC) National (AOM02 004). T E was the recipient of a grant (ASPIRE Young Investigator Research Awards in Endocrinology) supported by Pfizer.

\section{Acknowledgements}

The authors wish to thank the patients and their families who participated in this study and physicians who referred the patients reported in this paper. They also sincerely thank N. Pouvreau for technical assistance and C. Stott for the review of the manuscript.

\section{References}

1 Roberts AE, Allanson JE, Tartaglia M \& Gelb BD. Noonan syndrome. Lancet 2013381 333-342. (doi:10.1016/S0140-6736(12)61023-X)

2 Tartaglia M, Gelb BD \& Zenker M. Noonan syndrome and clinically related disorders. Best Practice \& Research. Clinical Endocrinology \& Metabolism 201125 161-179. (doi:10.1016/j.celrep.2015.09.019)

3 Pandit B, Sarkozy A, Pennacchio LA, Carta C, Oishi K, Martinelli S, Pogna EA, Schackwitz W, Ustaszewska A, Landstrom A et al. Gain-offunction RAF1 mutations cause Noonan and LEOPARD syndromes with hypertrophic cardiomyopathy. Nature Genetics 200739 1007-1012. (doi:10.1038/ng2073)

4 Digilio MC, Conti E, Sarkozy A, Mingarelli R, Dottorini T, Marino B, Pizzuti A \& Dallapiccola B. Grouping of multiple-lentigines/LEOPARD and Noonan syndromes on the PTPN11 gene. American Journal of Human Genetics 200271 389-394. (doi:10.1086/341528)

5 Tajan M, de Rocca Serra A, Valet P, Edouard T \& Yart A. SHP2 sails from physiology to pathology. European Journal of Medical Genetics 201558 509-525. (doi:10.1016/j.ejmg.2015.08.005)

6 Dance M, Montagner A, Salles JP, Yart A \& Raynal P. The molecular functions of Shp2 in the Ras/Mitogen-activated protein kinase (ERK1/2) pathway. Cell Signalling 200820 453-459. (doi:10.1073/ pnas.1119803109)

7 Kontaridis MI, Swanson KD, David FS, Barford D \& Neel BG. PTPN11 (Shp2) mutations in LEOPARD syndrome have dominant negative, not activating, effects. Journal of Biological Chemistry 2006281 6785-6792. (doi:10.1074/jbc.M513068200)

8 Tartaglia M, Martinelli S, Stella L, Bocchinfuso G, Flex E, Cordeddu V, Zampino G, Burgt I, Palleschi A, Petrucci TC et al. Diversity and functional consequences of germline and somatic PTPN11 mutations in human disease. American Journal of Human Genetics $2006 \mathbf{7 8}$ 279-290. (doi:10.1086/499925)

$9 \mathrm{Yu} \mathrm{ZH,} \mathrm{Zhang} \mathrm{RY,} \mathrm{Walls} \mathrm{CD,} \mathrm{Chen} \mathrm{L,} \mathrm{Zhang} \mathrm{S,} \mathrm{Wu} \mathrm{L,} \mathrm{Liu} \mathrm{S} \mathrm{\&}$ Zhang ZY. Molecular basis of gain-of-function LEOPARD syndromeassociated SHP2 mutations. Biochemistry 201453 4136-4151. (doi:10.1021/bi5002695)

10 Edouard T, Combier JP, Nedelec A, Bel-Vialar S, Metrich M, ConteAuriol F, Lyonnet S, Parfait B, Tauber M, Salles JP et al. Functional effects of PTPN11 (SHP2) mutations causing LEOPARD syndrome on epidermal growth factor-induced phosphoinositide 3-kinase/
AKT/glycogen synthase kinase 3beta signaling. Molecular and Cellular Biology 201030 2498-2507. (doi:10.1128/MCB.00646-09)

11 Marin TM, Keith K, Davies B, Conner DA, Guha P, Kalaitzidis D, Wu X, Lauriol J, Wang B, Bauer M et al. Rapamycin reverses hypertrophic cardiomyopathy in a mouse model of LEOPARD syndrome-associated PTPN11 mutation. Journal of Clinical Investigation 2011121 1026-1043. (doi:10.1172/JCI44972)

12 Romano AA, Allanson JE, Dahlgren J, Gelb BD, Hall B, Pierpont ME, Roberts AE, Robinson W, Takemoto CM \& Noonan JA. Noonan syndrome: clinical features, diagnosis, and management guidelines. Pediatrics 2010126 746-759. (doi:10.1542/peds.2009-3207)

13 Ranke MB, Heidemann P, Knupfer C, Enders H, Schmaltz AA \& Bierich JR. Noonan syndrome: growth and clinical manifestations in 144 cases. European Journal of Pediatrics 1988148 220-227. (doi:10.1007/BF00441408)

14 Witt DR, Keena BA, Hall JG \& Allanson JE. Growth curves for height in Noonan syndrome. Clinical Genetics 198630 150-153. (doi:10.1111/cge.1986.30.issue-3)

15 Malaquias AC, Brasil AS, Pereira AC, Arnhold IJ, Mendonca BB, Bertola DR \& Jorge AA. Growth standards of patients with Noonan and Noonan-like syndromes with mutations in the RAS/MAPK pathway. American Journal of Medical Genetics A 2012 158A 2700-2706. (doi:10.1002/ajmg.a.35519)

16 Usher R \& McLean F. Intrauterine growth of live-born Caucasian infants at sea level: standards obtained from measurements in 7 dimensions of infants born between 25 and 44 weeks of gestation. Journal of Pediatrics 196974 901-910. (doi:10.1016/j.jaac.2014.12.012)

17 Onis M OA, Borghi E, Siyam A, Nishida C \& Siekmann J. Development of a WHO growth reference for school-aged children and adolescents. Bulletin of the World Health Organization 200785 660-667. (doi:10.2471/BLT.00.000000)

18 Ancel PY, Goffinet F, Group E-W, Kuhn P, Langer B, Matis J, Hernandorena X, Chabanier P, Joly-Pedespan L, Lecomte B et al. Survival and morbidity of preterm children born at 22 through 34 weeks gestation in France in 2011: results of the EPIPAGE-2 cohort study. JAMA Pediatrics 2015169 230-238. (doi: 10.1001/ jamapediatrics.2014.3351)

19 Limal JM, Parfait B, Cabrol S, Bonnet D, Leheup B, Lyonnet S, Vidaud M \& Le Bouc Y. Noonan syndrome: relationships between genotype, growth, and growth factors. Journal of Clinical Endocrinology and Metabolism 200691 300-306. (doi:10.1210/jc.2005-0983)

20 Yoshida R, Hasegawa T, Hasegawa Y, Nagai T, Kinoshita E, Tanaka Y, Kanegane H, Ohyama K, Onishi T, Hanew K et al. Protein-tyrosine phosphatase, nonreceptor type 11 mutation analysis and clinical assessment in 45 patients with Noonan syndrome. Journal of Clinical Endocrinology and Metabolism 200489 3359-3364. (doi:10.1210/ jc.2003-032091)

21 Araki T, Chan G, Newbigging S, Morikawa L, Bronson RT \& Neel BG. Noonan syndrome cardiac defects are caused by PTPN11 acting in endocardium to enhance endocardial-mesenchymal transformation. PNAS 2009106 4736-4741. (doi:10.1073/pnas.0810053106)

22 Krenz M, Gulick J, Osinska HE, Colbert MC, Molkentin JD \& Robbins J. Role of ERK1/2 signaling in congenital valve malformations in Noonan syndrome. PNAS 2008105 18930-18935. (doi:10.1073/pnas.0806556105)

23 Nakamura T, Colbert M, Krenz M, Molkentin JD, Hahn HS, Dorn GW 2nd \& Robbins J. Mediating ERK 1/2 signaling rescues congenital heart defects in a mouse model of Noonan syndrome. Journal of Clinical Investigation 2007117 2123-2132. (doi:10.1172/JCI30756)

24 Chen PC, Wakimoto H, Conner D, Araki T, Yuan T, Roberts A, Seidman C, Bronson R, Neel B, Seidman JG et al. Activation of multiple signaling pathways causes developmental defects in mice with a Noonan syndrome-associated Sos1 mutation. Journal of Clinical Investigation 2010120 4353-4365. (doi:10.1172/JCI43910)

25 De Rocca Serra-Nedelec A, Edouard T, Treguer K, Tajan M, Araki T, Dance M, Mus M, Montagner A, Tauber M, Salles JP et al. Noonan 
syndrome-causing SHP2 mutants inhibit insulin-like growth factor 1 release via growth hormone-induced ERK hyperactivation, which contributes to short stature. PNAS $20121094257-4262$.

26 Wu X, Simpson J, Hong JH, Kim KH, Thavarajah NK, Backx PH, Neel BG \& Araki T. MEK-ERK pathway modulation ameliorates disease phenotypes in a mouse model of Noonan syndrome associated with the Raf1(L613V) mutation. Journal of Clinical Investigation $2011 \mathbf{1 2 1}$ 1009-1025. (doi:10.1172/JCI44929)

27 Binder G, Neuer K, Ranke MB \& Wittekindt NE. PTPN11 mutations are associated with mild growth hormone resistance in individuals with Noonan syndrome. Journal of Clinical Endocrinology and Metabolism 200590 5377-5381. (doi:10.1210/jc.2005-0995)

28 Murakami S, Balmes G, McKinney S, Zhang Z, Givol D \& de Crombrugghe B. Constitutive activation of MEK1 in chondrocytes causes Stat1-independent achondroplasia-like dwarfism and rescues the Fgfr3-deficient mouse phenotype. Genes and Development 200418 290-305. (doi:10.1101/ gad.1179104)

29 Ono K, Karolak MR, Ndong Jde L, Wang W, Yang X \& Elefteriou F. The ras-GTPase activity of neurofibromin restrains ERK-dependent FGFR signaling during endochondral bone formation. Human Molecular Genetics 201322 3048-3062. (doi:10.1093/hmg/ddt162)
30 Naski MC, Colvin JS, Coffin JD \& Ornitz DM. Repression of hedgehog signaling and BMP4 expression in growth plate cartilage by fibroblast growth factor receptor 3. Development 1998125 4977-4988.

31 Caux F, Plauchu H, Chibon F, Faivre L, Fain O, Vabres P, Bonnet F, Selma ZB, Laroche L, Gerard M et al. Segmental overgrowth, lipomatosis, arteriovenous malformation and epidermal nevus (SOLAMEN) syndrome is related to mosaic PTEN nullizygosity. European Journal of Human Genetics 200715 767-773. (doi:10.1038/ sj.ejhg.5201823)

32 Lindhurst MJ, Sapp JC, Teer JK, Johnston JJ, Finn EM, Peters K, Turner J, Cannons JL, Bick D, Blakemore L et al. A mosaic activating mutation in AKT1 associated with the Proteus syndrome. New England Journal of Medicine 2011365 611-619. (doi:10.1056/NEJMoa1104017)

33 Binder G, Grathwol S, von Loeper K, Blumenstock G, Kaulitz R, Freiberg C, Webel M, Lissewski C, Zenker M \& Paul T. Health and quality of life in adults with Noonan syndrome. Journal of Pediatrics 2012161 501-505 e501. (doi:10.1016/j.jpeds.2012.02.043)

34 Tajan M, Batut A, Cadoudal T, Deleruyelle S, Le Gonidec S, Saint Laurent C, Vomscheid M, Wanecq E, Treguer K, De Rocca Serra-Nedelec A et al. LEOPARD syndrome-associated SHP2 mutation confers leanness and protection from diet-induced obesity. PNAS 2014111 E4494-E4503.

Received 15 September 2015

Revised version received 12 January 2016

Accepted 22 February 2016 